\title{
Ventilation and Oxygenation Management in the Traumatic Brain Injury Setting
}

\author{
Behzad Saberi* \\ MD, Medical Research, Esfahan, Iran \\ *Corresponding author: Behzad Saberi, MD, Medical Research, Esfahan, Iran
}

\section{Introduction}

Early management of ventilation and oxygenation in the patients with traumatic brain injury, can be of importance to reduce secondary injury risks and improve outcomes. Increasing in the intracranial pressure of the patients with traumatic brain injury is an important risk which these patients are faced with. Hypocapnia due to hyperventilation and vasoconstriction in the brain's blood vessels as the result, causes reduction in blood flow. Therefore, the risk of secondary injury due to hypoperfusion and ischemia would increase. It is recommended to keep $\mathrm{PaCO}_{2}$ levels in the range between 35 and 40 in these settings. Minimizing the bag-ventilating of the patients with traumatic brain injury who have been intubated, is an important note which should be kept in mind to reduce the risk of hyperventilation in such patients. These patients should be placed on the mechanical ventilator at the earliest possibility. 7 to 8 liters/min can be a reasonable starting minute ventilation in these settings, because of the possibility of presenting hypermetabolic state in the patients with traumatic brain injury [1-5].

Permissive hypercapnia is inappropriate in these settings since these patients are at risk for Acute Respiratory Distress Syndrome. In such settings Capnography and $\mathrm{ABG}$ should be considered to correlate End-tidal $\mathrm{CO}_{2}$ with the Partial pressure of carbon dioxide. Normoxia is important in such settings to prevent secondary injury and improve the outcomes. The ABG should be checked in a time period about 15 to 20 minutes after intubation. Based on oxygen-haemoglobin dissociation curve in different cases, $\mathrm{FiO}_{2}$, $\mathrm{PaO}_{2}$ and $\mathrm{O}_{2}$ saturation ranges should be defined. Hemodynamic of the patients with traumatic brain injury should be managed appropriately. Hypotension and hypertension in these patients should be corrected to avoid further complications. It is important for the neurointensive care professionals to have knowledge about appropriate management of ventilation and oxygenation in the patients with traumatic brain injury.

\section{References}

1. Pelosi P, Ferguson ND, Frutos-Vivar F, Anzueto A, Putensen C, et al. (2011) Management and outcome of mechanically ventilated neurologic patients. Crit Care Med 39(6): 1482-1492.

2. Asehnoune K, Mrozek S, Seguin P, Dahyot Fizelier C et al. (2017) A multifaceted strategy to reduce ventilation-associated mortality in braininjured patients. The BI-VILI project: a nationwide quality improvement project. Intensive Care Med 43(7): 345-314.

3. Carney N, Totten AM, O’Reilly C, Ullman JS2, Hawryluk GW et al. (2017) Guidelines for the management of severe traumatic brain injury, fourth edition. Neurosurgery 80: 6-15.

4. Davis DP, Idris AH, Sise MJ (2006) Early ventilation and outcome in patients with moderate to severe traumatic brain injury. Crit Care Med 34: 1202-1208.

5. Esteban A, Anzueto A, Frutos F, Brochard L, Stewart TE et al. (2002) Characteristics and outcomes in adult patients receiving mechanical ventilation: a 28-day international study. JAMA 287: 345-355. 
(C) (P) This work is licensed under Creative

DOI: $10.32474 /$ GJAPM.2020.03.000154

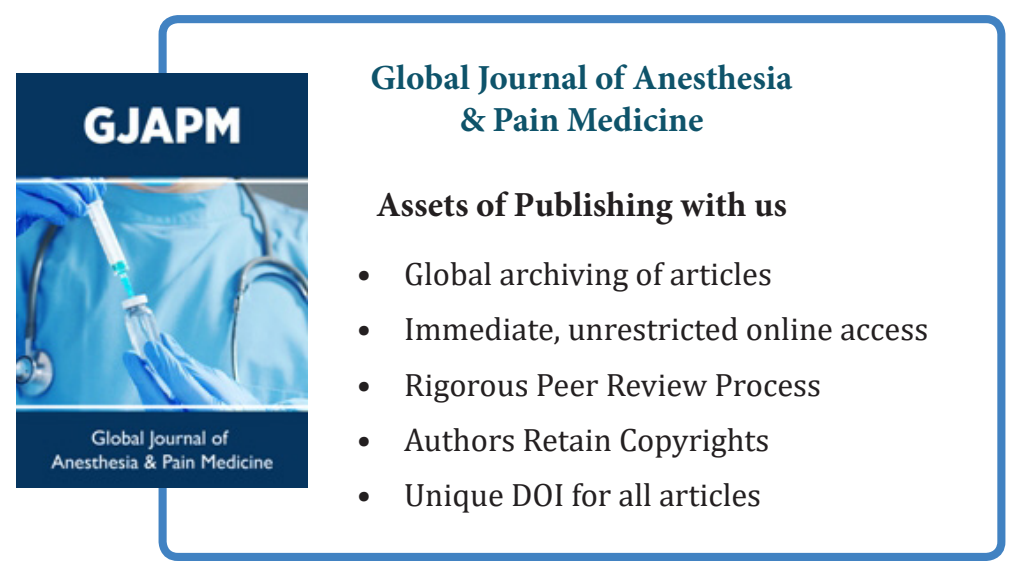

